
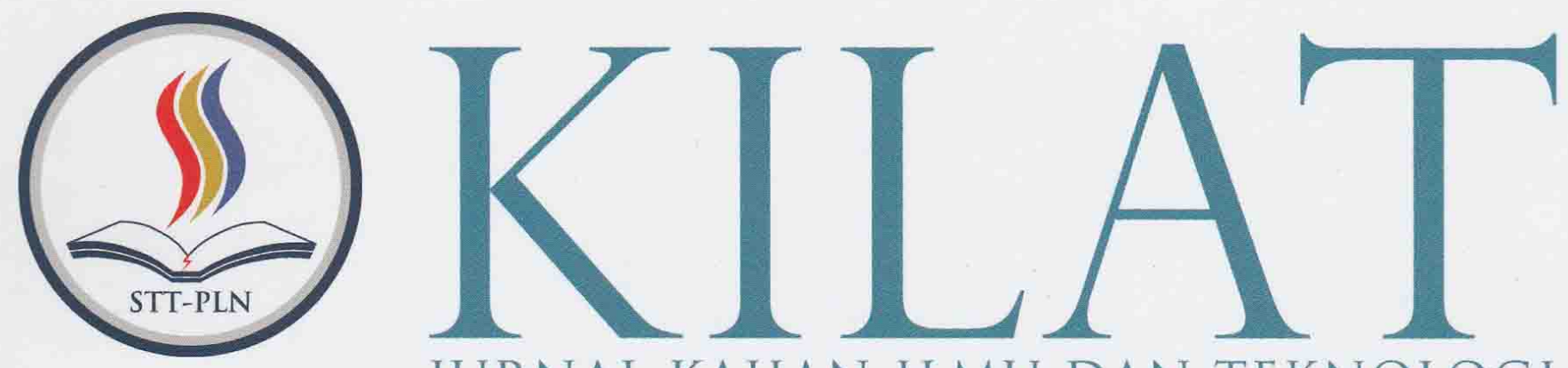
JURNAL KAJIAN ILMU DAN TEKNOLOGI

Dine Tiara Kusuma:

M. Yoga Distra Sudirman: Yessy Fitriani

Emillia; Yuliansyah

Rosida Nur Aziza; Dhzillan Dzhalila

Ranti Hidayawanti

Dewi Arianti Wulandari; Hendra Jatnika; Yudhy S. Purwanto

Rr. Mekar Ageng Kinasti; Endah Lestari; Devita Mayasari

Faisal Piliang

Mauludi Manfaluthy

Pauzi Hasan; Peby Wahyu Purnawan

Rahmi Amir: Baginda Oloan Lubis

Sabar Hanadwiputra; Subandri

Ndaru Ruseno; Satria
PENDEKATAN METODE ALTMAN Z-SCORE DALAM PENENTUAN INSENTIF BONUS PEGAWAI

METODE YURIDIS PENGELOLAAN SAMPAH RUMAH TANGGA DAN SAMPAH SEJENIS DI STT-PLN

METODE KUANTITATIF DENGAN PENDEKATAN KLASIK PADA APLIKASI ANALISIS BUTIR SOAL SEBAGAI MEDIA EVALUASI PENENTUAN SOAL YANG BERKUALITAS

UPAYA TERTIB LISTRIK TERHADAP INSTALATIR KABEL DI DAERAH PADAT PENDUDUK (STUDY KASUS KEC. TAMBORA)

RANCANG BANGUN APLIKASI CLUSTERING DATA MINING MENGGUNAKAN METODE K-MEANS DAN K-MODES

POTENSI PEMANFAATAN LIMBAH PEMBAKARAN BATUBARA (BOTTOM ASH) PADA PLTU SEBAGAI MEDIA TANAM DALAM UPAYA MENGURANGI PENCEMARAN LINGKUNGAN

PEMILIHAN PERANGKAT LUNAK PEMINDAHAN BERKAS DALAM MENINGKATKAN PEMANFAATAN TELEPON PINTAR

PEMANFAATAN RADIASI ENERGI TEGANGAN 150 KV UNTUK LAMPU LED PENERANGAN JALAN

KAJIAN PERBANDINGAN PERFORMANSI ROUTING PROTOCOL RIPNG, OSPFV3 DAN EIGRPVG PADA JARINGAN IPV6

PERANCANGAN PROGRAM PENGELOLAAN DATA KEUANGAN PASIEN RAWAT JALAN BPJS PADA RUMAH SAKIT GRAHA JUANDA BEKASI

ANALISA DAN IMPLEMENTASI VTP DENGAN ETHERCHANNEL TYPE LACP

PENGEMBANGAN RANCANG BANGUN SISTEM KESISWAAN DENGAN MENGGUNAKAN FRAMEWORK MVC

(MODEL VIEW CONTROLLER)

\begin{tabular}{|l|l|l|l|l|l|}
\hline KILAT & VOL.7 & NO.1 & HAL. 1 - 90 & APRIL 2018 & ISSN 2089 - 1245 \\
\hline
\end{tabular}




\title{
UPAYA TERTIB LISTRIK TERHADAP INSTALATIR KABEL DI DAERAH PADAT PENDUDUK (STUDY KASUS KEC. TAMBORA)
}

\author{
Ranti Hidayawanti \\ Teknik Sipil, STT PLN \\ ranti@sttpln.ac.id
}

\begin{abstract}
Electricity is a very important thing in everyday life, in the absence of electricity all things related to this heat energy will experience obstacles. The densely populated residential area located in Tambora Village, Kosambi District, West Jakarta, are a targeted area for an orderly area of electricity, where some of its people illegally stole electricity. This is very dangerous for users or harm PLN, for that criminal effort must be eradicated through the extension program or orderly socialization in order not to cause a fire. The method used is observation in the area of tambora village by looking at the connection installation used. The objectives of the program of orderly electricity socialization are: to give understanding to the people of Tambora Village due to electrical locking (stolen) and electrical installer failure of fire hazard due to short circuit.
\end{abstract}

Keywords: electricity, fire, kortsleting

\begin{abstract}
Abstrak
Listrik merupakan hal yang sangat penting dalam kehidupan sehari-hari, tanpa adanya listrik segala sesuatu yang berhubungan dengan energi panas ini akan mengalami hambatan. Daerah pemukiman padat penduduk yang berlokasi di Tambora Kecamatan Jakarta Barat merupakan daerah binaan untuk daerah tertib listrik, dimana beberapa masyarakatnya mencantol listrik secara ilegal. Hal ini sangat membahayakan bagi pengguna maupun merugikan kantor PLN, untuk itu upaya tindak kriminal tersebut harus diberantas sampai bersih melalui program penyuluhan atau sosialisasi tertib listrik agar tidak menimbulkan kebakaran. Metoda yang digunakan adalah observasi dikawasan Tambora dengan melihat sambungan instalatir yang digunakan. Tujuan dari program sosialisasi tertib listrik yaitu: memberikan pemahaman kepada masyarakat Tambora akibat pencantolan listrik dan kesalahan instalatir kabel listrik bahaya kebakaran akibat arus pendek.
\end{abstract}

Kata kunci: Listrik, kebakaran, korsleting

\section{PENDAHULUAN}

Listrik merupakan kebutuhan sangat penting bagi masyarakat yang beraktivitas pada wilayah yang komersial. Kebutuhan listrik pada wilayah yang padat mengakibatkan kepedulian masyarakat akan keselamatan sedikit berkurang khususnya di Jakarta yang mempunyai beberapa wilayah yang tidak teratur akan sambungan listrik serta instalatir yang salah. Beberapa masyarakat yang kurang pemahaman akan listrik, seperti pemakaian listrik di rumah yang lupa dicabut pemasangan terminal listrik yang berlebihan serta bahayanya.

Pemasangan listrik secara ilegal yang hanya menguntungkan diri sendiri, penggunaan perangkat listrik yang tidak standar, lingkungan listrik yang buruk dan lain-lain. Contoh prilaku tersebut bisa mengakibatkan adanya kebakaran akibat hubung arus pendek tegangan listrik, Oleh karena itu, diperlukannya sosialisasi mengenai pencegahan kebakaran akibat penggunaan listrik yang kurang dipahami oleh masyarakat di wilayah padat penduduk.

Kebakaran merupakan bahaya yang mempunyai dampak yang sangat luas meliputi kehidupan social dan ekonomi masyarakat yang mengalaminya. Kebakaran menimbulkan kerugian material, stagnasi kegiatan, kerusakan lingkungan, juga menimbulkan ancaman terhadap keselamatan jiwa manusia. Bencana banjir, gempa, dan datangnya badai, dengan kemajuan teknologi yang ada bisa didahului dengan datangnya peringatan awal yang memungkinkan untuk dapat menekan timbulnya kerugiandan korban jiwa. Tidak demikian halnya dengan bahaya kebakaran, bencana ini proses datangnya selalu tanpa dapat diperkirakan sebelumnya (unpredictible) sebagaimana bencana lain. Kapan, Apa penyebabnya, luas area serta seberapa besar dampak yang ditimbulkanya, adalah hal-hal yang tidak bisa diperkirakan sebelumnya. Teknologi yang ada hanya dapat membantu memberi peringatan dini, tetapi mempunyai kemampuan yang sangat terbatas untuk memberi waktu persiapan dan pertolongan dalam menghadapi bahayanya. Peringatan hanya dapat diberikan pada saat api atau kebakaran dalam keadaan sedang berlangsung. Sehingga cara yang paling efektif dalam menghadapi terjadinya bencana kebakaran tersebut adalah dengan menghindari dan meminimalkan kemungkinan-kemungkinan penyebab terjadinya bencana kebakaran.

Kebakaran adalah adanya api yang tidak dikehendaki. Peristiwa kebakaran diawali dengan pembakaran kemudian api tersebut sudah tidak dapat terkendali dan mengancam keselamatan jiwa 
dan harta benda. Ada dua jenis bahaya yang ditimbulkan sebagai akibat dari terjadinya kebakaranya itu kerugian material dan keselamatan jiwa manusia. Beberapa aspek penyelamatan sebenarnya lebih diarahkan dan diprioritaskan pada penyelamatan jiwa manusia terlebih dahulu, untuk kemudian meminimalkan kerugian pada tahap berikutnya. Sehingga pada prinsipnya, konsep penanggulangan kebakaran (fire safety) yang utama adalah penyelamatan jiwa manusia. Bahaya keselamatan jiwa manusia pada peristiwa kebakaran dapat diklasifikasikan: bahaya langsung (tersengat temperatur yang tinggi keracunan asap) dan bahaya tidak langsung (terluka, terjatuh, terserangsakit, mengalami shock/serangan psikologis).

Api tumbuh secara bertahap, dari mulai menyala, membesar, menghasilkan gas dan asap dari bahan yang terbakar, dan bila tidak dikontrol, ia akan mencapai tahap maksimal yang menghanguskan serta membahayakan keselamatan jiwa. Menurut Mantra (2005), secara teknis perkembangan api di dalam ruangan tertutup dapat dibagi menjadi 5 (lima) tahap:

\section{Tahap Penyalaan}

Tahap ini ditandai dengan munculnya api dalam ruangan. Proses timbulnya api dalam ruangan disebabkan oleh adanya energy panas yang mengenai material yang dapat terbakar dalam ruang. Energy panas tersebut bias berasala dari panas akibat ledakan kompor, tabung gas, hubungan singkat arus listrik, punting rokok membara, dll. Akibat dan gejala yang ditimbulkannya masih relative kecil sehingga kejadian pada tahap ini seringkali tidak diketahui.

\section{Tahap Pertumbuhan (Growth Period)}

Setelah tahap penyalaan, api mulai berkembang sebagai fungsi dari bahan bakar, dengan sedikit atau tanpa pengaruh dari ruangan. Udara yang ada di dalam ruangan masih cukup untuk mensuplai pembakaran. Jika material yang terbakar masih cukup banyak dan pertumbuhan api berlangsung terus sehingga menyebabkan temperature ruangan naik. Keadaan demikian disebut api dikendalikan bahan bakar. Pada tahap ini api masih teralokasi dan temperature ruangan masih relative rendah, dibawah $300^{\circ} \mathrm{C}$. tahap pertumbuhan ini merupakan yang paling baik untuk evakuasi penghuni dan sensor - sensor pencegah kebakaran harus sudah bekerja. Asap dan gas gas beracun masih sedikit sehingga ruangan masih cukup aman bagi tindakan evakuasi. Upaya pengendalian kebakaran sebaiknya dilakukan pada tahap ini, oleh karena selepas flashover api susah dikendalikan.

\section{Tahap Puncak (Flashover)}

Flashover secara umum didefinisikan sebagai masa transisi antara tahap pertumbuhan dengan tahap pembakaran penuh. Proses berlangsungnya sendiri sangat cepat, berkisar $300-600^{\circ} \mathrm{C}$. munculnya flashover disebabkan oleh adanya ketidakstabilan panas di dalam ruangan. Beberapa kriteria kapan terjadinya flashover yaitu:
Saat lidah api (flame) menyentuh langit langit.

- Saat lidah api (flame) mulai menjulur keluar bukaan

- Saat temperature lapis atas ruangan mencapai $300-600^{\circ} \mathrm{C}$.

- Saat timbul tingkat radiasi kritis pada lantai ruangan yang besarnya $2 \mathrm{~cm}^{2}$.

Ketika flashover tercapai, yang sebelumnya terbakar sebagian mendadak dan serentak terbakar seluruhnya. Jadi flashover adalah kondisi batas dimulainya kebakaran total dalam ruangan. Kecepatan pembakaran naik secara cepat sehingga api sukar dikendalikan. Oleh karena itu perkiraan kapan terjadinya flashover sangat penting dalam pengkajian perilaku pembakaran dalam ruangan.

\section{Tahap Pembakaran Penuh (Fully Developed \\ Fire) \\ Pada tahap ini kalor yang dilepaskan (heat} release) adalah yang paling besar, karena kebakaran terjadi diseluruh ruangan. Seluruh material dalam ruang terbakar, sehingga temperature dalam ruang menjadi sangat tinggi, mencapai $1200^{\circ} \mathrm{C}$. Pada tahap ini perkembangan api sangat dipengaruhi oleh dimensi dan bentuk ruangan, terutama lebar bukaan, karena udara dalam ruangan sendiri sudah tidak mampu mensuplai pembakaran sepenuhnya. Kondisi demikian biasa disebut sebagai api yang dikendalikan oleh ventilasi. Akibat yang mungkin timbul adalah rusaknya elemen - elemen akibat thermal stress, kerusakan pada komponen struktur pendukung, kemudian runtuhnya bangunan. Agar tidak terjadi keruntuhan struktur bangunan maka sejak perencanaan bangunan harus sudah diperhitungkan penggunaan struktur tahan api guna membatasi penjalaran kebakaran ke ruang - ruang lainnya diseluruh bangunan atau disebut kompatemenisasi ruangan.

\section{Tahap Surut (Decay)}

Tahap surut tercapai bila material sudah terbakar habis dan temperature ruangan berangsur turun. Selain penurunan temperature, ciri lain tahap ini adalah turunnya laju pembakaran. Pada tahap ini perkembangan api kembali sebagai fungsi dari material yang terbakar. Semakin menyusut bahan bahan yang dapat terbakar dalam ruangan semakin api surut.

Dalam suatu proses pembakaran, tidak semua tahap perkembangan api akan selalu terlalui, atau proses pembakaran mencapai semua tahap. Hal tersebut sangat tergantung dari kualitas dan kapasitas tiga unsur pembentukan api.

Secara defenisi, api dapat dijelaskan sebagai hasil reaksi cepat dari material terbakar, oksigen (O2) dan energy awal. Ketiga unsur tersebut adalah yang membentuk api.

Menurut Dinas Kebakaran dan Penaggulangan Bencana Provinsi DKI Jakarta menyebutkan $70 \%$ kebakaran yang terjadi di Jakarta disebabkan korsleting listrik serta kesalahan instalatir kabel listrik. 


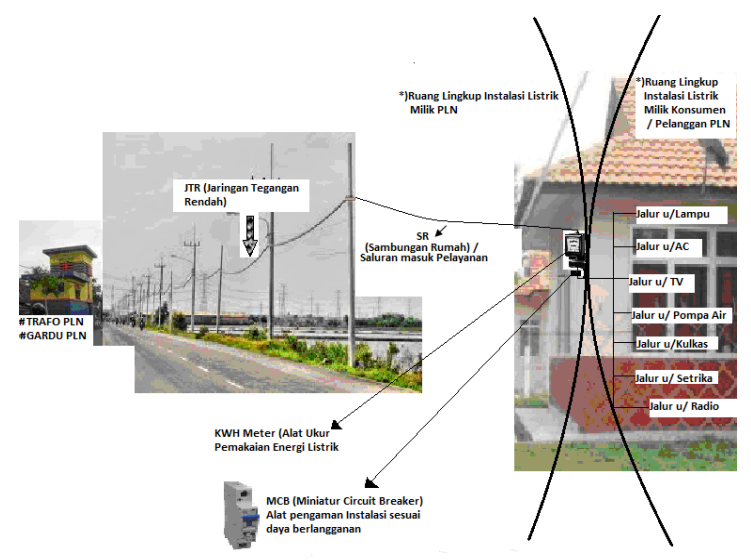

Gambar 1 : Batasan Tanggung Jawab PLN

Adapun klasifikasi sumber api berdasarkan sumbernya adalah sebagai berikut:

1. Api Kelas A, yang berasal dari benda padat seperti kayu, lastik, kain, kertas, dll

2. Api Kelas B, yang berasal dari benda gas dan cair.

3. Api Kelas C, yang berasal dari listrik (arus pendek / kortsleting)

4. Api Kelas D, yang berasal dari logam yang mudah terbakar seperti magnesium, alumunium, dll

5. Kategori lainnya, seperti oksidasi yang ekstrim yang berasal dari tempat tempat penampung seperti hydrogen peroksida, asam nitrit, dll

\section{Tujuan Penelitian}

1. Memberikan pemahaman kepada masyarakat tentang bahaya akibat pecantolan listrik secara ilegal dan kesalahan sambungan instalatir yang dapat menyebabkan kebakaran yang disebabkan oleh listrik dan upaya-upaya yang harus dilakukan agar terhindar dari kebakaran akibat korsleting listrik di wilayah Tambora Jakarta Barat.

2. Membuka wawasan agar masyarakat tidak tetap nekat mencantol listrik serta memperhatikan sambungan instalatir yang berakibat kebakaran yang disebabkan hubung arus singkat, kelebihan beban, penggunaan perangkat listrik yang tidak memenuhi standar nasional Indonesia dan lingkungan listrik yang buruk.

\section{METODE PENELITIAN}

\section{Persiapan}

Persiapan merupakan rangkaian kegiatan sebelum memulai penelitian. Dalam tahap persiapan disusun hal - hal yang harus dengan tujuan untuk efektifitas waktu dan pekerjaan penulisan tugas, tahap persiapan ini meliputi kegiatan antara lain menetukan perihal pokok pembahasan penelitian dan studi pustaka.

\section{- Pengumpulan Data}

Untuk dapat melakukan analisis yang baik, diperlukan data atau informasi, teori tentang konsep dasar dan alat bantu memadai, sehingga kebutuhan data mutlak diperlukan. Dalam tahap pengumpulan data pada saat pelaksanaan tugas data - data yang dijadikan bahan acuan dalam penyusunan tugas ini dapat diklasifikasikan dalam dua jenis data, yaitu Data Teknis dan Data Non Teknis.

a) Data Teknis

Adalah data yang berhubungan langsung dengan instalasi kabel listrik.

b) Data Non Teknis

Adalah data yang berfungsi sebagai penunjang dalam instalasi listrik seperti standar instalasi listrik dan perilaku masyarakat wilayah pemukiman yang sering melakukan pencantolan listrik secara illegal.

Langkah yang dilakukan setelah mengetahui data-data yang diperlukan adalah menentukan metode pengumpulan datanya.

Adapun metode pengumpulan data yang dilakukan adalah salah satunya melalui studi pustaka. Studi pustaka adalah pengumpulan data dengan data data dari hasil penyelidikan, penelitian, pedoman, maupun standar yang diperlukan dalam melakukan instalasi listrik di pemukiman.

\section{Penyajian Analisa}

Analisa dan pedoman yang dilakukan dalam melakukan instalasi listrik adalah sebagai berikut:

a) Pedoman SNI terkait standar intalasi listrik.

b) Hal hal yang mempengaruhi terjadinya kortsleting dikarenakan perilaku masyarakat sekitar yang sering melakukan pencantolan listrik secara illegal.

\section{Bagan Alur}

Berikut ini merupakan bagan alur dari penelitian:

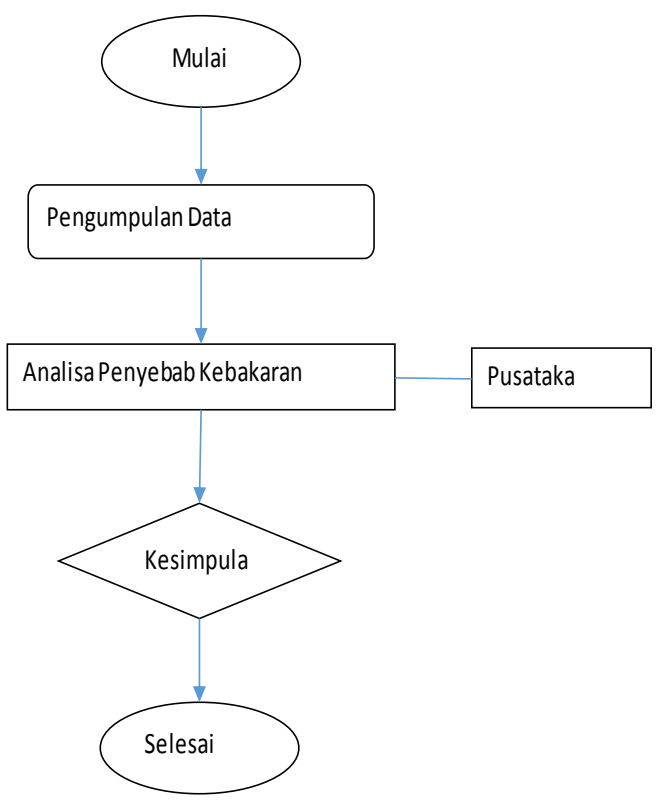

Gambar 2 : Metodologi Penelitian 


\section{Uraian Diagram Alir Metodologi}

a. Permasalahan

Mencermati perilaku masyarakat terkait penggunaan listrik dilingkungan padat penduduk dan meneliti seberapa besar dampaknya terhadap bahaya kebakaran.

b. Pengumpulan Data dan Metode Sampling Pada tahap pengumpulan data ini ada dua macam data yang dibutuhkan, yaitu Data Sekunder dan Data Primer. Data Sekunder adalah data yang telah ada, diperoleh dari instansi instansi yang berkepentingan. Sedangkan Data Primer merupakan data yang diambil secara langsung melalui survey pada lokasi yang bersangkutan.

c. Analisa Data

Data Primer yang akan dikumpulkan dari hasil wawancara / kuesioner merupakan data mentah. Agar data tersebut dapat lebih berguna bagi penelitian ini diperlukan suatu penyajian dan analisa data.

d. Studi Pendahuluan

Studi Pendahuluan dilakukan di lokasi daerah pemukiman padat penduduk yang berlokasi di Tambora Kecamatan Jakarta Barat guna mendapatkan gambaran umum kondisi lapangan. Pada kegiatan ini yang dilakukan adalah mengamati secara visual terhadap situasi yang diteliti dan ditunjang oleh studi pustaka untuk melakukan penelitian ini.

e. Kesimpulan

Menuliskan kesimpulan dari pengamatan dan analisa yang telah dilakukan termasuk juga memberikan saran saran jika diperlukan.

\section{HASIL DAN PEMBAHASAN}

Listrik merupakan suatu hal yang sangat dibutuhkan masyarakat untuk keperluan penerangan, disamping itu kebutuhan listrik tidak dapat dipisahkan dan sudah merupakan kebutuhan primer bagi sebagian besar masyarakat pada umumnya. Pencantolan bukanlah hal yang baik yang dapat dilakukan karena merupakan tindakan kriminal, disinilah peran kita sebagai orang yang peduli terhadap sesama.

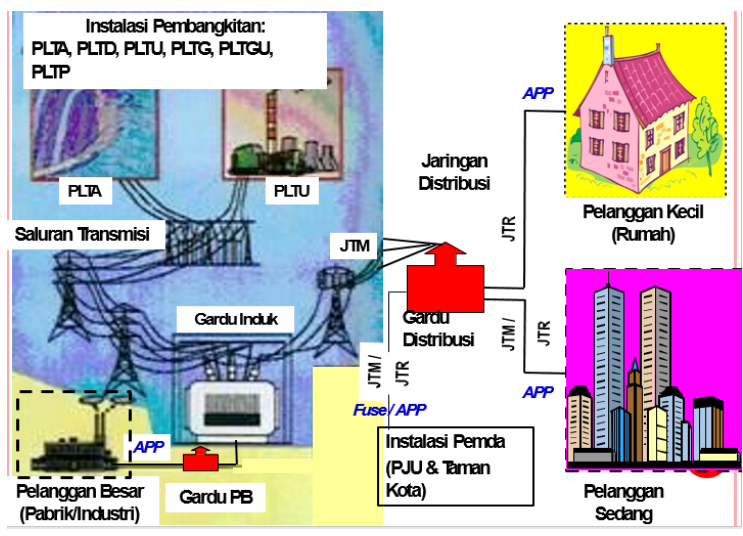

Gambar 3 : Batas lingkup Keselamatan Ketenagalistrikan

Berdasarkan data yang diperoleh dari Dinas Kebakaran dan Penanggulangan Bencana Provinsi
DKI Jakarta menyatakan bahwa 70\% kebakaran yang terjadi di Jakarta adalah akibat kortsleting listrik. Sampling dilakukan terhadap di Desa Tambora Jakarta Barat dimana pada pemukiman tersebut perilaku masyarakatnya banyak melakukan pencantolan listrik secara illegal yang berkontribusi terhadap pemicu kebakaran. Berdasarkan klasifikasi api sebagaimana dijelaskan diatas, api yang berasal dari dari listrik (arus pendek / kortsleting) merupakan api kelas $\mathrm{C}$.

Hal tersebut diatas menjadi perhatian tersendiri mengingat perilaku masyarakatnya yang kurang peduli terhadap dampak bahaya kortsleting listrik. Kebakaran dapat terjadi jika ada tiga unsur yaitu bahan yang mudah terbakar, oksigen dan percikan api. Sementara menurut data yang dikumpulkan oleh Dinas Kebakaran DKI sejak dari tahun 1992 s/d 1997 telah tejadi kebakaran sebanyak 4.244 kasus di mana yang 2135 kasus disebabkan karena konsleting listrik. Berarti $50 \%$ lebih dari total kasus kebakaran disebabkan oleh listrik. Hal ini karena perlengkapan listrik yang digunakan tidak sesuai dengan prosedur yang benar dan standar yang ditetapkan oleh LMK (Lembaga Masalah Kelistrikan) PLN, rendahnya kualitas peralatan listrik dan kabel yang digunakan, serta intalasi yang asal-asalan dan tidak sesuai peraturan.

Sekarang ini masih banyak pabrik perlengkapan listrik yang kualitas produknya rendah kemudian mensuplainya ke pasar. Hal ini tentunya akan dikonsumsi oleh instalatir dan pemakai listrik yang mengutamakan keuntungan tanpa memikirkan akibat fatal yang akan ditimbulkannya. Karena tingkat keamanan perlengkapan listrik ditentukan oleh kualitasnya. Jadi bagi para produsen, instalatir dan konsumen harus menyadari benar akan fungsi perlengkapan listrik yang akan digunakannya.

Penyebab kebakaran terkait dengan listrik dapat bermacam macam seperti:

\section{Human Error}

Hal ini karena awamnya masyarakat terhadap listrik sehingga sering kali bertindak sembrono atau teledor dalam menggunakan listrik atau tidak mengikuti prosedur dan metode penggunaan listrik secara benar menurut aturan PLN, sehingga terjadilah kebakaran itu yang tidak sedikit kerugiannya. Sedangkan salah satu usaha yang bisa dilakukan untuk menekan terjadinya kebakaran adalah dengan meningkatkan kesadaran masyarakat pengguna listrik untuk keperluan sehari-hari.

Seperti dalam membagi-bagi arus dengan menggunakan stop kontak bukannya dilakukan dengan semaunya tapi harus dilakukan sesuai peraturan supaya tidak menimbulkan kebakaran. Artinya jika jumlah steker yang dipasang pada suatu stop kontak melebihi batas maka akan menyebabkan kabel pada stop kontak itu menjadi panas. Jika panas itu terjadi dalam waktu yang relatif lama maka hal ini akan menyebabkan melelehnya terminal utama dan akhirnya secara pelan-pelan terjadilah hubung singkat. Kemudian dari panas itu munculah api yang akan merambat di sepanjang kabel dan jika isolator tidak mampu menahan panas maka akan terjadilah kebakaran. 
Untuk itu gunakanlah stop kontak sebagaimana mestinya. Dalam hal ini ada dua stop kontak; pertama stop kontak 200 Watt hanya digunakan untuk peralatan di bawah 500 - 1000 VA; ke dua jenis stop kontak tenaga yang digunakan untuk peralatan diatas $1000 \mathrm{VA}$.

\section{Hubungan singkat (kortsleting)}

Korseleting listrik (hubung singkat) terjadi karena adanya hubungan kawat positif dan kawat negatif yang beraliran listrik. Hal ini karena isolasi kabel rusak yang disebabkan gigitan binatang, sudah tua, mutu kabel jelek dan penampang kabel terlalu kecil yang tidak sesuai dengan beban listrik yang mengalirinya. Kemudian di sekitar terjadinya percikan api isolasi kabel sudah mencapai titik bakar. Suhu isolasi kabel dapat mencapai titik bakar karena arus listrik yang lewat kabel jauh lebih besar dari kemampuan kabelnya.

Misalnya kabel untuk ukuran 12 ampere dialiri arus listrik 16 ampere, karena kabel tersebut dipakai untuk menyambung banyak peralatan listrik akibatnya isolasi kabel menjadi panas. Jika pada suhu isolasi yang sedang tinggi itu terjadi percikan api maka kemungkinan besar bahan isolasi akan terbakar. Percikan api terjadinya hanya satu kali karena sikring langsung bekerja memutuskan aliran, namun itu cukup untuk menyebabkan kebakaran dan kebakaran yang diakibatkan oleh percikan api akan tetap berlangsung karena karet isolasi yang sudah mencapai suhu bakar akan terbakat terus secara merembet. Untuk bahan isolasi tertentu lelehan kabel terbakar yang jatuh tidak akan segera padam, tetapi masih menyala dengan waktu yang cukup untuk membakar, inilah salah satu kemungkinan penyebab kebakaran.

Selain dari itu ada juga kebakaran karena listrik yang disebabkan karena telah terjadi kontak yang tidak sempurna yaitu kadang-kadang tersambung kadang-kadang tidak sehingga menimbulkan percikan api. Contohnya dapat dilihat pada saklar lampu pada malam hari sehingga ruangan menjadi gelap dan menimbulkan percikan api karena kontaknya sudah rusak akibatnya kotak kontak hangus terbakar. Jika kontak yang tidak sempurna dilewati oleh arus, maka lambat laun panas akan naik. Kemudian panas yang terjadi akan merambat memanaskan material sekitar termasuk bahan isolasi. Jika bahan menjadi mudah terbakar karena suhunya tinggi maka percikan api akan sangat mudah menyebabkan kebakaran.

\section{Kabel}

Sistim kabel konvesional di mana kabel tertanam dalam infrastruktur memang sulit untuk mengikuti perubahan karena infrastrukturnya yang tidak mudah dirobah. Sementara itu dewasa ini penggunaan peralatan elektronis dan elektris diperkantoran semakin banyak berarti penggunaan kabelnya semakin banyak pula, seperti untuk komunikasi suara, data dan untuk catu daya. Dengan demikian kabel-kabel itu berseliweran karena tata kabel belum diatur dengan baik. Hal ini jika salah satu kabel mengeluarkan api maka kabel yang lain mudah terbakar akibatnya akan fatal.

Sedangkan arus maksimum yang diizinkan mengalir pada penghantar kabel tentunya jangan sampai menimbulkan pemanasan yang menyebabkan lembeknya logam penghantar. Pelembekan logam penghantar merupakan fungsi waktu dan suhu. Upaya untuk menekan bahaya kebakaran yang ditimbulkan oleh hubung pendek arus bisa dilakukan melalui kabelnya. Artinya dalam menggunakan kabel kita harus mengetahui fungsinya yaitu untuk keamanan gedung dan keselamatan jiwa manusia. Menggunakan kabel yang tidak memenuhi standar biasanya hanya akan mengundang resiko kebakaran yang lebih besar.

\section{Instalatir}

Biro instalatir adalah suatu badan yang terdaftar dan mendapat izin kerja dari PT PLN untuk merencanakan dan mengerjakan pembangunan atau pemasangan peralatan ketenagalistrikan. Sistim instalasi yang asal-asalan dan tidak sesuai peraturan dapat menyebabkan kebakaran.

Selain hal tersebut diatas, Pengubahan instalasi yang dilakukan sendiri tanpa sepengetahuan dari instalatur yang melakukan pekerjaan awal. Kemudian pekerjaan tersebut dikerjakan tidak sesuai prosedur. Untuk itu apabila masyarakat pengguna listrik akan melakukan perubahan instalasi pada bangunannya dianjurkan menghubungi instalatur resmi yang telah diakui kemampuannya. Selain dari itu hendaknya dalam pemasangan panel box hendaknya digunakan bahan yang kedap air dan anti tikus. Karena air dan tikus sangat mungkin menyebabkan terjadinya hubung singkat arus listrik. Perilaku masyarakat yang sering melakukan pencantolan listrik secara illegal juga menjadi salah satu factor dalam hal ini karena dilakukan oleh oknum yang tidak bertanggung jawab.

Berikut adalah hal hal yang harus dihindari agar tidak menyebabkan kebakaran akibat arus pendek:

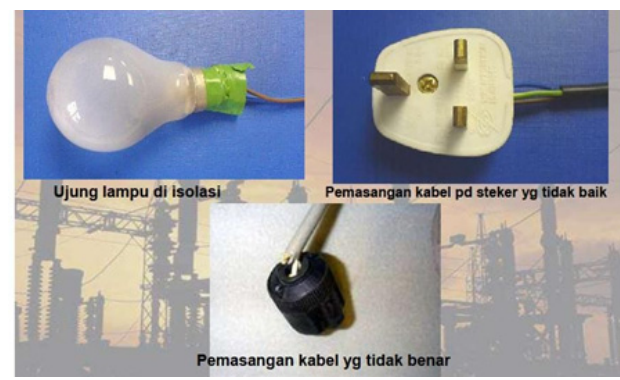

Gambar 4: Potensi tersentuh langsung pada kawat yang bertegangan karena pemasangan kabel yang tidak benar

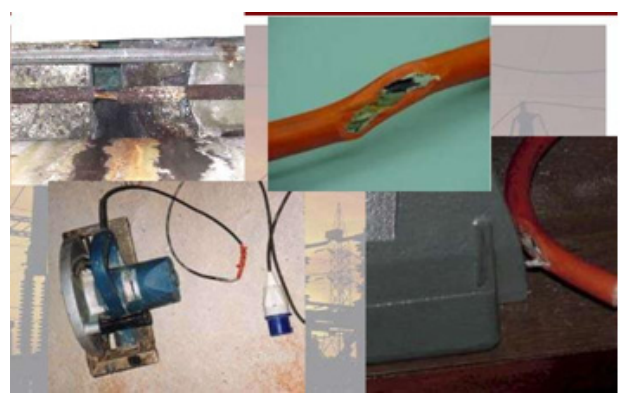

Gambar 5: Bagian kabel yang terbuka 


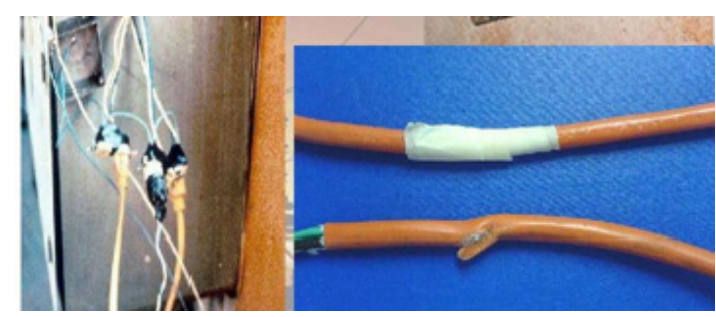

Gambar 6: Isolasi kabel yang buruk

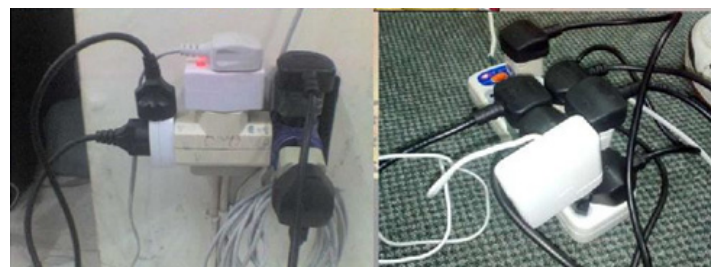

Gambar 7 : Overload pada sistem instalasi listrik

\section{KESIMPULAN DAN SARAN}

\section{Kesimpulan}

1. Jangan menumpuk stop kontak pada satu sumber listrik.

2. Gunakan pemutus arus listrik (sekering) yang sesuai dengan daya tersambung, jangan dilebihkan atau dikurangi

3. Kabel-kabel listrik yang terpasang di rumah jangan dibiarkan ada yang terkelupas atau dibiarkan terbuka.

4. Jauhkan sumber-sumber listrik seperti stop kontak, saklar dan kabel-kabel dari jangkauan anak-anak.

5. Biasakan menggunakan material listrik seperti kabel, saklar, stop kontak, steker (kontak tusuk) yang telahterjamin kualitasnya dan berlabel SNI (Standar Nasional Indonesia)/LMK (Lembaga Masalah Kelistrikan)/SPLN (Standar PLN).

6. Jangan pernah mencoba mencantol listrik, mengutak-atik $\mathrm{KWH}$ Meter atau menggunakan listrik secara tidak sah

7. Biasakan bersikap hati-hati, waspada dan tidak ceroboh dalam menggunakan listrik.

\section{Saran}

1. Pangkaslah pepohonan yang ada dihalaman rumah jika sudah mendekati atau menyentuh jaringan listrik dan berkoordinasi dengan pihak PLN dalam pelaksanaannya.

2. Hindari pemasangan antene televisi terlalu tinggi sehingga bisa mendekati atau menyentuh jaringan listrik.

\section{DAFTAR PUSTAKA}

1. Marsudi (2006), Pengantar Dasar Listrik, Marsudi (2006), Pengantar Dasar Listrik, Erlangga

2. Robert L. Boylestad (2006), Electronic Devices \& Circuit Theory, Pearson

3. Roger Fourquet, 2008, Heat Power and Light, USA, Edward Elgan publishing

4. Norman S. Nise, 2008, Control Systems Engineering, USA, John Wiley inc

5. Richard G. Lyons, 2010, Understand Digital Signal Processing, Pearson

6. Miller et all, 2011, Power Electronic Control in Electrical System, oxford, Newnes

7. V.K Menta, 2011, Principles of Electronics, New Delhi

8. UU No.30 / 2009 tentang Ketenagalistrikan

9. Mantra, I.B.G.W., 2005. Kajian Penanggulangan Bahaya Kebakaran Pada Perumahan. Jurnal Pemukiman 3:61

10. Suprapto, 2008. Tinjauan Eksistensi Standar Stamdar Proteksi Kebakaran dan Penerapannya Dalam Mendukung Implementasi Peraturan Keselamatan Bangunan, PPIS. Departemen Pekerjaan Umum, Bandung. 